\title{
Beppu's Nomogram Score Is an Independent Prognostic Factor for Colorectal Liver Metastasis Receiving Perioperative Chemotherapy and/or Targeted Therapy
}

\author{
AKIO HIGUCHI ${ }^{1 *}$, TORU AOYAMA ${ }^{1 *}$, KEISUKE KAZAMA ${ }^{1}$, MASAAKI MURAKAWA $^{1}$, YOSUKE ATSUMI ${ }^{1}$, \\ YUSUKE KATAYAMA $^{1}$, KOJI NUMATA ${ }^{1}$, SHO SAWAZAKI ${ }^{1}$, MASAKATSU NUMATA ${ }^{1}$, SUMITO SATO ${ }^{1}$, \\ NOBUHIRO SUGANO ${ }^{1}$, HIROSHI TAMAGAWA ${ }^{2}$, HIROYUKI MUSHIAKE ${ }^{2}$, TAKASHI OSHIMA ${ }^{1}$, \\ NORIO YUKAWA ${ }^{2}$, SOICHIRO MORINAGA ${ }^{1}$, YASUSHI RINO ${ }^{2}$, MUNETAKA MASUDA ${ }^{2}$ and MANABU SHIOZAWA ${ }^{1}$ \\ ${ }^{1}$ Department of Gastrointestinal Surgery, Kanagawa Cancer Center, Yokohama, Japan; \\ ${ }^{2}$ Department of Surgery, Yokohama City University, Yokohama, Japan
}

\begin{abstract}
Background/Aim: We investigated the impact of Beppu's nomogram on colorectal liver metastasis in patients receiving perioperative chemotherapy and/or targeted therapy. Patients and Methods: This study included 43 patients who underwent primary hepatic resection for colorectal liver metastasis at the Kanagawa Cancer Center from June 2006 to March 2011. The patients were classified as having a Beppu's nomogram score $\leq 9$ (low-risk group) or $\geq 10$ (high-risk group). The risk factors for the disease-free survival (DFS) were identified. Results: The respective DFS rates at 1,2, and 3 years after surgery were $72.0 \%, 43.3 \%$, and $17.3 \%$ in the low-risk group and $27.8 \%, 16.7 \%$, and $8.3 \%$ in the high-risk group, the difference being significant $(p=0.009)$. The multivariate analysis showed that Beppu's nomogram score $\geq 10$ was a significant independent risk factor for the DFS. Conclusion: Beppu's nomogram score was an independent prognostic factor for colorectal liver metastasis in patients receiving perioperative chemotherapy and/or targeted therapy. Thus, Beppu's nomogram might be a useful tool for predicting the risk of recurrence after hepatectomy, even in the era of newly-developed chemotherapy.
\end{abstract}

This article is freely accessible online.

*Akio Higuchi and Toru Aoyama contributed equally to this study.

Correspondence to: Akio Higuchi, Department of Gastrointestinal Surgery, Kanagawa Cancer Center, 2-3-2 Nakao, Asahi-ku, Yokohama 241-8515, Japan. Tel: +81 455202222, e-mail: rg6ahgc@asahi-net.or.jp

Key Words: Beppu's nomogram score, colorectal liver metastasis, disease-free survival.
Colorectal cancer is the third-most commonly diagnosed cancer in men and the second-most commonly diagnosed in women, with an estimated 1.4 million new cases and 693,900 deaths occurring in 2012 (1). Complete resection is essential for cure (2). Although the resection rate has gradually increased, some patients experience recurrence even after curative surgery (3).

Patients with advanced-stage disease often develop recurrence to the peritoneum, liver, lymph nodes or other organs, even after curative surgery. Among these patients, liver metastasis is the most common pattern (4-6), and more than $50 \%$ will likely develop liver metastases during the course of their disease (7). According to several guidelines, curative liver resection is the most effective therapy for metastatic colorectal cancer $(2,8,9)$. However, the prognosis for this cohort of patients is heterogeneous because of a variety of clinical and tumor-specific factors (10). To predict the prognosis of patients with colorectal liver metastasis, some groups have advocated the use of disease-specific nomograms as superior prognostic tools (11-13).

A nomogram is a statistical tool that generates a simple graphical representation of a complex statistical model (14). It helps clinicians graphically determine the individualized, patient-specific survival rapidly, without doing any complex calculations. Beppu's nomogram is a tool for predicting the disease-free survival (DFS) after hepatectomy for colorectal liver metastasis (11). The nomogram consists of six preoperative patient factors (CA19-9 level, timing of liver metastasis, primary tumor lymph node status, number of liver tumors, largest diameter of liver tumor, and extrahepatic metastatic disease). The six factors are scored and predict the DFS at 3 and 5 years. As it includes only six preoperative patient factors, this nomogram is very simple and easy to use. However, one limitation associated with Beppu's nomogram is its time-related bias, as it was established 
between 2000 and 2004. The patients who were evaluated in order to develop Beppu's nomogram received surgery alone because no effective chemotherapy for colorectal liver metastasis had been established at the time (11). Recently, however, a number of effective treatments, such as oxaliplatin- and irinotecan-based chemotherapy and/or targeted therapy, for colorectal liver metastasis have been introduced (15-20). Therefore, whether or not Beppu's nomogram still has a clinical relevance for colorectal liver metastasis in patients receiving perioperative chemotherapy and/or target therapy is unclear. We hypothesized that Beppu's nomogram would still be applicable for patients receiving oxaliplatin- or irinotecan-based chemotherapy and/or targeted therapy.

To confirm our hypothesis, we investigated whether or not Beppu's nomogram has clinical relevance for patients with colorectal liver metastasis receiving perioperative chemotherapy and/or targeted therapy.

\section{Patients and Methods}

Patients. The study subjects were selected from the medical records of consecutive patients who underwent primary hepatic resection for colorectal liver metastasis at the Kanagawa Cancer Center from June 2006 to March 2011. The inclusion criteria were as follows: 1) patients with a common pathological type of colorectal cancer (according to the International Union Against Cancer (UICC) TNM 7th edition) and 2) patients in whom curative liver resection was successful. Patients with the concomitant use of thermal ablation were excluded.

Follow-up. Patients were followed up at Kanagawa Cancer Center. Hematological tests and physical examinations were performed at least every three months, for five years. In the patients who received perioperative chemotherapy, hematological tests and physical examinations were performed every two or three weeks, and CT examinations were performed every two or three months during perioperative chemotherapy. The CEA and CA19-9 tumor marker levels were checked at least every three months for five years. Patients underwent a CT examination every three months during the first three years after surgery and then every six months up to five years after surgery.

Beppu's nomogram. The parameters evaluated in this study included the 1) estimated timing of liver metastasis, 2) primary tumor lymph node status, 3) number of tumors, 4) largest tumor diameter, 5) extrahepatic metastatic disease, and 6) CA19-9 levels. Beppu's nomogram was calculated using these six parameters (11). The predicted DFS calculated with Beppu's nomogram was compared with the actual DFS.

Statistical analyses. The DFS was defined as the period between liver resection surgery and recurrence or death, whichever came first. The data of the patients who did not experience an event were censored on the date of the final observation. The DFS was evaluated by univariate and multivariate analyses. DFS curves were calculated using the Kaplan-Meier method and were compared by the log-rank test. A Cox proportional hazards model was used to perform the univariate and multivariate survival analyses. $p$-Values of $<0.05$ were considered to indicate statistical significance. The survival data were obtained from hospital records or from the city registry system. The SPSS software program (v11.0 J Win; SPSS, Chicago, IL, USA) was used for all statistical analyses. This study was approved by the institutional review board of the Kanagawa Cancer Center (approval number: epidemiological study-69).

\section{Results}

General characteristics. Forty-three patients were evaluated in the present study. The patient characteristics are described in Table I. The median age was 64.9 (range $=42-85$ ) years. Twenty-three patients were male, and 20 were female. Histologically, 40 patients $(93.0 \%)$ were tub, and $3(7.0 \%)$ were others. Twenty-two patients had a primary colon tumor, and 21 had a primary rectal lesion. One patient was TNM stage I, 6 were stage II, 5 were stage IIIA, 4 were stage IIIB, and 27 were stage IV. Preoperative chemotherapy was performed in 14 patients (oxaliplatin-based in 5 patients, irinotecan-based in 2 patients, molecular-targeted therapy in 7 patients). Postoperative chemotherapy was performed in 27 patients (fluorouracil-based in 10 patients, oxaliplatin-based in 14 patients, irinotecan-based in 5 patients, moleculartargeted therapy in 1 patient).

The DFS and nomogram score. After a median follow-up of 13.6 months (range=1.5-96.1 months), the 1-, 2, and 3-year DFS rates were $53.5 \%, 31.6 \%$, and $13.2 \%$. The median DFS time was 13.6 months.

The subjects were divided into three groups based on their nomogram score $(0-4,5-9$, and $\geq 10$ points $)$ and the DFS of each group was investigated. There was a significant difference in the DFS between the group with a score of 5-9 points and those with $\geq 10$ points (Table II). We then defined those with a nomogram score of $\leq 9$ points as the low-risk of recurrence group and those with a score of $\geq 10$ points as the high-risk of recurrence group. The DFS curve of high-risk group was significantly worse than low-risk group (Figure 1). We investigated the risk factors of recurrence after hepatic metastasis resection. In a univariate analysis, a high nomogram score $(\geq 10)$ was a risk factor for recurrence after liver resection. In the multivariate analysis, a high nomogram score $(\geq 10)$ was also a risk factor for recurrence after liver resection (Table III). No factors related to postoperative chemotherapy were risk factors for recurrence.

\section{Discussion}

The aim of the present study was to evaluate the clinical relevance of Beppu's nomogram for patients with colorectal liver metastasis receiving perioperative chemotherapy and/or targeted therapy. The major findings were that DFS differed significantly according to Beppu's nomogram score, and 
Table I. General patient characteristics.

\begin{tabular}{|c|c|c|}
\hline & Number of patients & Percentage \\
\hline Age (years) & $64.9(42-85)$ & \\
\hline \multicolumn{3}{|l|}{ Gender } \\
\hline Male & 23 & 53.5 \\
\hline Female & 20 & 46.5 \\
\hline \multicolumn{3}{|l|}{ Histological type } \\
\hline Tub & 40 & 93.0 \\
\hline Others & 3 & 7.0 \\
\hline \multicolumn{3}{|l|}{ Location } \\
\hline Colon & 22 & 51.2 \\
\hline Rectum & 21 & 48.8 \\
\hline \multicolumn{3}{|l|}{ T stage } \\
\hline $\mathrm{T} 1$ & 1 & 2.3 \\
\hline $\mathrm{T} 2$ & 5 & 11.6 \\
\hline $\mathrm{T} 3$ & 14 & 32.6 \\
\hline $\mathrm{T} 4$ & 23 & 53.5 \\
\hline \multicolumn{3}{|l|}{$\mathrm{N}$ stage } \\
\hline No & 10 & 23.3 \\
\hline N1 & 15 & 34.9 \\
\hline $\mathrm{N} 2$ & 12 & 27.9 \\
\hline N3 & 5 & 11.6 \\
\hline N4 & 1 & 2.3 \\
\hline \multicolumn{3}{|l|}{ Preoperative chemotherapy regimen } \\
\hline No chemotherapy & 29 & 67.4 \\
\hline Oxaliplatin- or irinotecan-based & 7 & 16.3 \\
\hline With molecular-targeted drugs & 7 & 16.3 \\
\hline \multicolumn{3}{|l|}{ Postoperative chemotherapy regimen } \\
\hline No chemotherapy & 17 & 39.5 \\
\hline Fluorouracil-based & 10 & 23.3 \\
\hline Oxaliplatin- or irinotecan-based & 15 & 34.9 \\
\hline With molecular-targeted drugs & 1 & 2.3 \\
\hline
\end{tabular}

Beppu's nomogram score was an independent prognostic factor. Thus, Beppu's nomogram might be a useful tool for predicting the risk of recurrence after hepatectomy, even in the era of newly developed chemotherapy.

Regarding the clinical relevance of Beppu's nomogram for colorectal liver metastasis, we observed a significant difference in DFS according to Beppu's nomogram score. Several reports have described the relationship between Beppu's nomogram score and DFS. For example, Okuno et al. (21) reported that Beppu's nomogram score is a marker of poor DFS. Two hundred and thirty-four patients with colorectal liver metastases who underwent hepatic resection were evaluated using Beppu's nomogram. Among them, 93 patients received oxaliplatin- or irinotecan-based prehepatectomy chemotherapy. The relationship between Beppu's nomogram score and DFS was then examined. In the calibration analysis, DFS differed significantly among the quintiles, and the calibration plot was close to the prospective line, indicating excellent calibration. Okuno et al. stated that these results indicate that Beppu's nomogram is a useful tool for predicting the risk of recurrence after hepatectomy (22).
Table II. The comparison of the survival rates stratified by patient characteristics.

\begin{tabular}{|c|c|c|c|c|c|}
\hline Characteristics & $\begin{array}{c}\text { Number } \\
\text { of } \\
\text { patients }\end{array}$ & $\begin{array}{l}\text { 1-year } \\
\text { survival } \\
\text { rate }(\%)\end{array}$ & $\begin{array}{l}\text { 2-year } \\
\text { survival } \\
\text { rate }(\%)\end{array}$ & $\begin{array}{l}\text { 3-year } \\
\text { survival } \\
\text { rate }(\%)\end{array}$ & $p$-Value \\
\hline Age (years) & & & & & 0.985 \\
\hline$\leq 60$ & 16 & 43.8 & 37.5 & 15.0 & \\
\hline$>60$ & 27 & 59.3 & 28.3 & 12.1 & \\
\hline Gender & & & & & 0.670 \\
\hline Male & 23 & 52.2 & 29.0 & 9.7 & \\
\hline Female & 20 & 55.0 & 34.3 & 17.1 & \\
\hline Location & & & & & 0.130 \\
\hline Colon & 22 & 68.2 & 44.1 & 16.5 & \\
\hline Rectum & 21 & 38.1 & 19.0 & 9.5 & \\
\hline Nomogram score & & & & & 0.001 \\
\hline $0-4$ & 14 & 78.6 & 42.9 & 7.1 & \\
\hline $5-9$ & 12 & 66.7 & 48.6 & 38.9 & \\
\hline $10-$ & 17 & 23.5 & 11.8 & 0 & \\
\hline UICC $\mathrm{T}$ status & & & & & 0.647 \\
\hline $\mathrm{T} 1-\mathrm{T} 3$ & 20 & 45.0 & 30.0 & 10.0 & \\
\hline $\mathrm{T} 4$ & 23 & 60.9 & 32.8 & 16.4 & \\
\hline Lymph node metastasis & & & & & 0.087 \\
\hline$<4$ & 25 & 72.0 & 43.3 & 13.0 & \\
\hline$\geq 4$ & 18 & 27.8 & 16.7 & 16.7 & \\
\hline Lymphovascular invasion & & & & & 0.615 \\
\hline Absent & 6 & 66.7 & 33.3 & 16.7 & \\
\hline Present & 37 & 67.6 & 31.4 & 12.6 & \\
\hline Chemotherapy after & & & & & \\
\hline hepatectomy & & & & & 0.189 \\
\hline Absent & 17 & 44.4 & 27.8 & 5.6 & \\
\hline Present & 26 & 60.0 & 33.9 & 19.4 & \\
\hline Number of liver tumors & & & & & 0.143 \\
\hline 1 & 26 & 69.2 & 37.8 & 16.8 & \\
\hline $2-4$ & 10 & 30.0 & 30.0 & 15.0 & \\
\hline$\geq 5$ & 7 & 28.6 & 14.3 & 0 & \\
\hline $\begin{array}{l}\text { Extrahepatic } \\
\text { metastatic disease }\end{array}$ & & & & & 0.091 \\
\hline Absent & 36 & 55.6 & 35.9 & 15.0 & \\
\hline Present & 7 & 42.9 & 0 & 0 & \\
\hline
\end{tabular}

UICC: Union for International Cancer Control.

Data were collected and assessed in 727 hepatectomized patients with colorectal liver metastases between 2000 and 2004 at the 11 institutions of the "Project Committee of the Liver" in the Japanese Society of Hepato-Biliary-Pancreatic Surgery. Six preoperative factors were selected to create the nomogram for the DFS: synchronous metastases, 3 points; primary lymph node positive, 3 points; number of tumors (24), 4 points and ( $\geq 5), 9$ points; largest tumor diameter $>5 \mathrm{~cm}$, 2 points; extrahepatic metastasis at hepatectomy, 4 points; and preoperative carbohydrate antigen $19-9$ level $>100,4$ points. The estimated median DFS time was easily calculated by the nomogram: $>8.4$ years for patients with 0 points, 1.9 years for those with 5 points, and 1.0 years for those with 10 points, and the rate was $<0.6$ years for those with more than 10 points. 


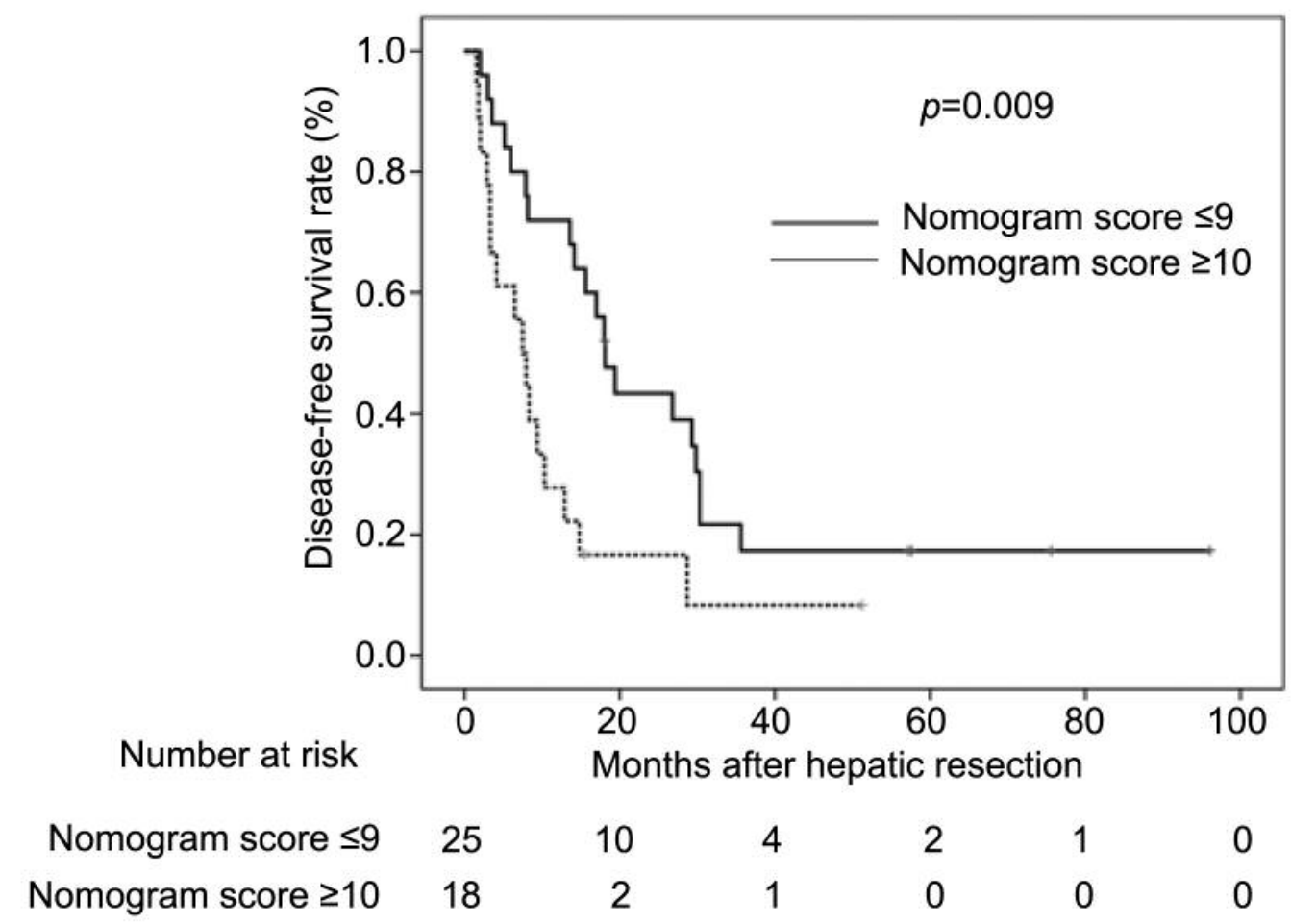

Figure 1. The disease-free survival curves of Beppu's nomogram score $\leq 9$ (low-risk group) and $\geq 10$ (high-risk group).

However, in 2005, new cytotoxic agents, such as oxaliplatin and irinotecan, were approved for use in Japan. Therefore, whether or not Beppu's nomogram still had clinical relevance for colorectal liver metastasis in patients receiving these new cytotoxic agents has been unclear. However, Okuno et al. showed in their study that Beppu's nomogram is a useful tool for predicting the risk of recurrence after hepatectomy, even in patients who had received the newly available cytotoxic agents (22).

Regarding the cut-off value of Beppu's nomogram score, we investigated the 1-, 2-, and 3-year DFS rates by classifying patients into three groups according to the nomogram score. There was a significant difference in the DFS between the patients with a nomogram score of 5-9 points and those with scores of $\geq 10$ points. A score between 9 and 10 points was considered the optimal cut-off point for classification, so scores of $\leq 9$ points were considered to indicate a low risk of recurrence, while scores of $\geq 10$ points indicated a high risk. Okuno et al. (22) also investigated 50 patients with colorectal liver metastasis who had undergone primary hepatic resection at Kyoto University Hospital from January 2005 to November 2009. They defined a nomogram score of $\leq 5$ points as indicating a low risk of recurrence and that of $\geq 6$ points as indicating a high risk. The DFS time of the high-risk group (score $\geq 6$ ) was shorter than that of the low-risk group (score $\leq 5)$ (19.5 vs. 51.2 months), albeit without significance $(p=0.28)$. Our cut-off point of 9 points differed from Okuno's cut-off point. However, they divided the low- and high-risk groups based on the nomogram scores of the relapsed (mean=6.96) and relapse-free groups (mean 5.26), whereas we set our cut-off point based on the DFS rate. The optimal cut-off point should be clarified conclusively in the future.

Care should be practiced when interpreting the current results, as there are several potential limitations associated with this study. First, this study was a retrospective, singlecenter study with a relatively small sample size. Beppu's nomogram score was calculated from the patient's records. Thus, our findings might have been obtained by chance. Furthermore, this study might have selection bias. Second, the optimal cut-off value of Beppu's nomogram score is unclear. Therefore, future studies should focus on this issue. Considering these limitations, the current results should be validated in other series with a larger number of patients.

In conclusion, Beppu's nomogram score was an independent prognostic factor for colorectal liver metastasis patients receiving perioperative chemotherapy and/or targeted therapy. Beppu's nomogram may therefore be a useful tool for predicting the risk of recurrence after hepatectomy, even in the era of newly developed chemotherapy. 
Table III. Results of univariate and multivariate Cox proportional hazards analyses of the clinicopathological factors for recurrence-free survival.

\begin{tabular}{|c|c|c|c|c|c|c|c|}
\hline \multirow[t]{2}{*}{ Factors } & \multirow[b]{2}{*}{ Number } & \multicolumn{3}{|c|}{ Univariate analysis } & \multicolumn{3}{|c|}{ Multivariate analysis } \\
\hline & & OR & $95 \% \mathrm{CI}$ & $p$-Value & OR & $95 \% \mathrm{CI}$ & $p$-Value \\
\hline Age (years) & & & & 0.985 & & & \\
\hline$>60$ & 27 & 1.000 & & & & & \\
\hline$\leq 60$ & 16 & 1.006 & $0.509-1.989$ & & & & \\
\hline Gender & & & & 0.671 & & & \\
\hline Female & 20 & 1.000 & & & & & \\
\hline Male & 23 & 1.154 & $0.596-2.232$ & & & & \\
\hline Location & & & & 0.136 & & & \\
\hline Colon & 22 & 1.000 & & & & & \\
\hline Rectum & 21 & 1.648 & $0.854-3.180$ & & & & \\
\hline Nomogram score & & & & 0.011 & & & 0.012 \\
\hline$\leq 9$ & 25 & 1.000 & & & 1.000 & & \\
\hline$\geq 10$ & 18 & 2.428 & $1.224-4.817$ & & 4.840 & $1.419-16.510$ & \\
\hline UICC $\mathrm{T}$ status & & & & 0.649 & & & \\
\hline $\mathrm{T} 1-\mathrm{T} 3$ & 20 & 1.000 & & & & & \\
\hline $\mathrm{T} 4$ & 23 & 1.165 & $0.605-2.243$ & & & & \\
\hline Lymph node metastasis & & & & 0.478 & & & \\
\hline$<4$ & 25 & 1.000 & & & & & \\
\hline$\geq 4$ & 18 & 1.280 & $0.648-2.527$ & & & & \\
\hline Lymphovascular invasion & & & & 0.618 & & & \\
\hline Absent & 6 & 1.000 & & & & & \\
\hline Present & 37 & 1.272 & $0.493-3.281$ & & & & \\
\hline Chemotherapy after hepatectomy & & & & 0.152 & & & \\
\hline Present & 26 & 1.000 & & & & & \\
\hline Absent & 17 & 1.620 & $0.838-3.135$ & & & & \\
\hline Number of liver tumors & & & & 0.069 & & & \\
\hline 1 & 26 & 1.000 & & & & & \\
\hline$\geq 2$ & 17 & 1.880 & $0.951-3.713$ & & & & \\
\hline Extrahepatic metastatic disease & & & & 0.099 & & & \\
\hline Absent & 36 & 1.000 & & & & & \\
\hline Present & 7 & 2.141 & $0.866-5.293$ & & & & \\
\hline
\end{tabular}

UICC: Union for International Cancer Control.

\section{Conflicts of Interest}

The Authors have no conflicts of interest to declare regarding this study.

\section{Authors' Contributions}

Akio Higuchi and Toru Aoyama made substantial contributions to conception and design. Akio Higuchi, Toru Aoyama, Keisuke Kazama, Masaaki Murakawa, Yosuke Atsumi, Yusuke Katayama, Koji Numata, Sho Sawazaki, Masakatsu Numata, Sumito Sato, Nobuhiro Sugano, Hiroshi Tamagawa, Hiroyuki Mushiake, Takashi Oshima, Norio Yukawa, Soichiro Morinaga, Yasushi Rino, Munetaka Masuda And Manabu Shiozawa made substantial contributions to acquisition of data, or analysis and interpretation of data and have been involved in drafting the manuscript or revising it critically for important intellectual content. Akio Higuchi and Toru Aoyama have given final approval of the version to be published. Each author should have participated sufficiently in the work to take public responsibility for appropriate portions of the content; and agreed to be accountable for all aspects of the work in ensuring that questions related to the accuracy or integrity of any part of the work are appropriately investigated and resolved. All Authors read and approved the final manuscript.

\section{References}

1 Ferlay J, Soerjomataram I, Dikshit R, Eser S, Mathers C, Rebelo M, Parkin DM, Forman D and Bray F: Cancer incidence and mortality worldwide: sources, methods and major patterns in GLOBOCAN 2012. Int J Cancer 136(5): E359-386, 2015. PMID: 25220842. DOI: $10.1002 / \mathrm{ijc} .29210$

2 National Comprehensive Care Network: Clinical Practice Guidelines in Oncology (NCCNGuidelines ${ }^{\circledR}$ ). Available from: http://www.nccn.org/professionals/physician_gls/f_guidelines.

3 Boland CR, Sinicrope FA, Brenner DE and Carethers JM: Colorectal cancer prevention and treatment. Gastroenterology 118(2 Suppl 1): S115-128, 2000. PMID: 10868902.

4 Riihimaki M, Hemminki A, Sundquist $\mathrm{J}$ and Hemminki K: Patterns of metastasis in colon and rectal cancer. Sci Rep 6: v29765, 2016. PMID: 27416752. DOI: 10.1038/srep29765

5 Eisenberg B, Decosse JJ, Harford F and Michalek J: Carcinoma of the colon and rectum: the natural history reviewed in 1704 patients. Cancer 49(6): 1131-1134, 1982. PMID: 7059938. 
6 Van Cutsem E, Rivera F, Berry S, Kretzschmar A, Michael M, DiBartolomeo M, Mazier MA, Canon JL, Georgoulias V, Peeters $\mathrm{M}$, Bridgewater $\mathbf{J}$ and Cunningham D: Safety and efficacy of first-line bevacizumab with FOLFOX, XELOX, FOLFIRI and fluoropyrimidines in metastatic colorectal cancer: the BEAT study. Ann Oncol 20(11): 1842-1847, 2009. PMID:19406901. DOI: $10.1093 /$ annonc/mdp233

7 Manfredi S, Lepage C, Hatem C, Coatmeur O, Faivre J and Bouvier AM: Epidemiology and management of liver metastases from colorectal cancer. Ann Surg 244(2): 254-259, 2006. PMID: 16858188. DOI: $10.1097 / 01$ sla.0000217629.94941.cf

8 JSCCR Guidelines 2019 for the Treatment of Colorectal Cancer.

9 Van Cutsem E, Cervantes A, Adam R, Sobrero A, Van Krieken JH, Aderka D, Aranda Aguilar E, Bardelli A, Benson A, Bodoky G, Ciardiello F, D'Hoore A, Diaz-Rubio E, Douillard J Y, Ducreux M, Falcone A, Grothey A, Gruenberger T, Haustermans K, Heinemann V, Hoff P, Kohne C H, Labianca R, Laurent-Puig P, Ma B, Maughan T, Muro K, Normanno N, Osterlund P, Oyen W J, Papamichael D, Pentheroudakis G, Pfeiffer P, Price T J, Punt C, Ricke J, Roth A, Salazar R, Scheithauer W, Schmoll H J, Tabernero J, Taieb J, Tejpar S, Wasan H, Yoshino T, Zaanan A and Arnold D: ESMO consensus guidelines for the management of patients with metastatic colorectal cancer. Ann Oncol 27(8): 13861422, 2016. PMID: 19406901. DOI: 10.1093/ annonc/mdp233

10 Compton CC: Colorectal carcinoma: diagnostic, prognostic, and molecular features. Mod Pathol 16(4): 376-388, 2003. PMID: 12692203. DOI: 10.1097/01 .mp.0000062859.46942.93

11 Beppu T, Sakamoto Y, Hasegawa K, Honda G, Tanaka K, Kotera Y, Nitta H, Yoshidome H, Hatano E, Ueno M, Takamura, H, Baba H, Kosuge T, Kokudo N, Takahashi K, Endo I, Wakabayashi G, Miyazaki M, Uemoto S, Ohta T, Kikuchi K, Yamaue $H$, Yamamoto $\mathrm{M}$ and Takada T: A nomogram predicting disease-free survival in patients with colorectal liver metastases treated with hepatic resection: multicenter data collection as a Project Study for Hepatic Surgery of the Japanese Society of Hepato-BiliaryPancreatic Surgery. J Hepatobiliary Pancreat Sci 19(1): 72-84, 2012. PMID: 22020927. DOI: 10.1007/s00534-011-0460-z

12 Kattan MW, Gonen M, Jarnagin WR, DeMatteo R, D'Angelica M, Weiser M, Blumgart LH and Fong Y: A nomogram for predicting disease-specific survival after hepatic resection for metastatic colorectal cancer. Ann Surg 247(2): 282-287, 2008. PMID: 18216534. DOI: 10.1097/SLA.0b013e31815ed67b

13 Kanemitsu Y and Kato T: Prognostic models for predicting death after hepatectomy in individuals with hepatic metastases from colorectal cancer. World J Surg 32(6): 1097-1107, 2008. PMID: 18200429. DOI: $10.1007 / \mathrm{s} 00268-007-9348-0$

14 Weiser MR, Landmann RG, Kattan MW, Gonen M, Shia J, Chou J, Paty PB, Guillem JG, Temple LK, Schrag D, Saltz LB and Wong WD: Individualized prediction of colon cancer recurrence using a nomogram. J Clin Oncol 26(3): 380-385, 2008. PMID: 18202413. DOI: $10.1200 /$ jco.2007.14.1291

15 Nordlinger B, Sorbye H, Glimelius B, Poston GJ, Schlag PM, Rougier P, Bechstein WO, Primrose JN, Walpole ET, FinchJones M, Jaeck D, Mirza D, Parks R W, Collette L, Praet M, Bethe U, Van Cutsem E, Scheithauer W and Gruenberger T: Perioperative chemotherapy with FOLFOX4 and surgery versus surgery alone for resectable liver metastases from colorectal cancer (EORTC Intergroup trial 40983): a randomised controlled trial. Lancet 371(9617): 1007-1016, 2008. PMID: 18358928. DOI: $10.1016 / \mathrm{s} 0140-6736(08) 60455-9$
16 Beppu T, Miyamoto Y, Sakamoto Y, Imai K, Nitta H, Hayashi $\mathrm{H}$, Chikamoto $\mathrm{A}$, Watanabe $\mathrm{M}$, Ishiko $\mathrm{T}$ and Baba $\mathrm{H}$ : Chemotherapy and targeted therapy for patients with initially unresectable colorectal liver metastases, focusing on conversion hepatectomy and long-term survival. Ann Surg Oncol 21: S405413, 2014. PMID: 24570379. DOI: 10.1245/s10434-014-3577-x

17 Bokemeyer C, Bondarenko I, Makhson A, Hartmann JT, Aparicio J, de Braud F, Donea S, Ludwig H, Schuch G, Stroh C, Loos A H, Zubel A and Koralewski P: Fluorouracil, leucovorin, and oxaliplatin with and without cetuximab in the first-line treatment of metastatic colorectal cancer. J Clin Oncol 27(5): 663-671, 2009. PMID: 19114683. DOI: 10.1200/jco.2008. 20.8397

18 Douillard JY, Siena S, Cassidy J, Tabernero J, Burkes R, Barugel M, Humblet Y, Bodoky G, Cunningham D, Jassem J, Rivera, F, Kocakova I, Ruff P, Blasinska-Morawiec M, Smakal M, Canon J L, Rother M, Oliner K S, Wolf M and Gansert J: Randomized, phase III trial of panitumumab with infusional fluorouracil, leucovorin, and oxaliplatin (FOLFOX4) versus FOLFOX4 alone as first-line treatment in patients with previously untreated metastatic colorectal cancer: the PRIME study. J Clin Oncol 28(31): 4697-4705, 2010. PMID: 20921465. DOI: $10.1200 /$ jco. 2009.27 .4860

19 Falcone A, Ricci S, Brunetti I, Pfanner E, Allegrini G, Barbara C, Crino L, Benedetti G, Evangelista W, Fanchini L, Cortesi, E, Picone V, Vitello S, Chiara S, Granetto C, Porcile G, Fioretto L, Orlandini C, Andreuccetti M and Masi G: Phase III trial of infusional fluorouracil, leucovorin, oxaliplatin, and irinotecan (FOLFOXIRI) compared with infusional fluorouracil, leucovorin, and irinotecan (FOLFIRI) as first-line treatment for metastatic colorectal cancer: the Gruppo Oncologico Nord Ovest. J Clin Oncol 25(13): 1670-1676, 2007. PMID: 17470860. DOI: $10.1200 /$ jco.2006.09.0928

20 Cremolini C, Loupakis F, Antoniotti C, Lupi C, Sensi E, Lonardi S, Mezi S, Tomasello G, Ronzoni M, Zaniboni A, Tonini G, Carlomagno C, Allegrini G, Chiara S, D'Amico M, Granetto C, Cazzaniga M, Boni L, Fontanini G and Falcone A: FOLFOXIRI plus bevacizumab versus FOLFIRI plus bevacizumab as first-line treatment of patients with metastatic colorectal cancer: updated overall survival and molecular subgroup analyses of the openlabel, phase 3 TRIBE study. Lancet Oncol 16(13): 1306-1315, 2015. PMID: 26338525. DOI: 10.1016/s1470-2045(15) 00122-9

21 Okuno M, Hatano E, Seo S, Taura K, Yasuchika K, Nakajima A, Yazawa T, Furuyama H, Kawamoto H, Yagi S, Nishitai R, Fujikawa T, Arimoto A, Zaima M, Yoshimura T, Terajima H, Kaihara S, Manaka D, Tanaka A and Uemoto S: Indication for neoadjuvant chemotherapy in patients with colorectal liver metastases based on a nomogram that predicts disease-free survival. J Hepatobiliary Pancreat Sci 21(12): 881-888, 2014. PMID: 25155418. DOI: 10.1002/jhbp.149

22 Okuno M, Hatano E, Nakamura K, Kasai Y, Nishio T, Seo S, Taura K, Mori A, Kaido T and Uemoto S: External validation of a nomogram predicting disease free survival after curative resection of liver metastasis from colorectal cancer. Jap J Gastroenterol Surg 9(47): 467-476, 2014. DOI: 10.5833/ jjgs.2013.0198

Received March 19, 2019

Revised April 26, 2019

Accepted April 30, 2019 